\title{
Principio de proporcionalidad y control constitucional de las leyes penales. Una comparación entre las experiencias de Chile y Colombia*
}

\author{
Gloria Patricia Lopera Mesa**
}

\begin{abstract}
RESUMEN
Se propone una aproximación a la utilización del principio de proporcionalidad en el control de las leyes penales en la jurisprudencia del Tribunal Constitucional chileno y de la Corte Constitucional colombiana, para indagar en qué medida tal herramienta ha contribuido al propósito de elevar la racionalidad en el control de las decisiones político criminales del legislador. Con tal fin se examinan las diferencias que median entre los sistemas de justicia constitucional de Chile y Colombia para, sobre esta base, indagar si en qué medida y en qué ocasiones los tribunales constitucionales de ambos países han formulado las preguntas e incorporado las exigencias que reclama la aplicación de aquella herramienta argumentativa en el control constitucional de las leyes penales sustantivas.
\end{abstract}

Principio de proporcionalidad - leyes penales - control de constitucionalidad

\section{Principle of proportionality and criminal law judicial review. A comparison between Chilean and Colombian experiences}

\begin{abstract}
This work proposes to review the use of the principle of proportionality in the decisions of the Constitutional Courts of Chile and Colombia dealing with judicial review of criminal law. The purpose of the work is to investigate how such a tool has contributed to the function of increasing the rationality in the control of criminal political decisions of the legislative branch. To do so, the work first examines the differences between the constitutional justice systems. On this basis, it is ascertained whether, to what extent and on what occasions these constitutional
\end{abstract}

* Este artículo es una reelaboración de la ponencia presentada en el seminario "Racionalidad de las Leyes Penales”, realizado en la Universidad Austral de Chile el 25 de marzo de 2010, bajo la dirección del profesor José Ángel Fernández.

** Abogada, Doctora en Derecho, Profesora Escuela de Derecho, Universidad EAFIT (Medellín, Colombia). Correo electrónico: glopera@eafit.edu.co

Artículo recibido el 29 de abril de 2011 y aceptado para su publicación por el Comité Editorial el 28 de octubre de 2011. 
courts bave asked the questions and incorporated the demands that the proportionality principle as an argumentative tool in the judicial review of substantive criminal law requires.

Principle of proportionality - criminal law - judicial review

$\mathrm{U}$ na de las principales características que acompaña el fenómeno de constitucionalización de los ordenamientos jurídicos es la puesta en marcha de mecanismos de control de constitucionalidad de las leyes. Aunque no existe una relación necesaria entre garantía de la supremacía constitucional y el establecimiento del control judicial de constitucionalidad de las leyes, lo cierto es que en la mayoría de los sistemas jurídicos constitucionalizados se ha optado por confiar dicha tarea a órganos de naturaleza jurisdiccional, carentes de legitimidad democrática directa, lo que ha dado lugar a la bien conocida objeción "contramayoritaria" que suele formularse en contra de la justicia constitucional. De ahí que el principal desafío que deben enfrentar los órganos encargados del control judicial de constitucionalidad de las leyes sea el compensar este déficit de legitimidad democrática de origen con una adecuada fundamentación de sus decisiones y con el diseño de procedimientos que amplíen las posibilidades de participación de los ciudadanos en el debate público en torno a la constitucionalidad de las leyes ${ }^{1}$. La solvencia argumentativa se convierte, entonces, en uno de los principales elementos de los que depende la "legitimidad de ejercicio" que deben ganar los Tribunales Constitucionales para cumplir su función de servir como alter ego institucional de las decisiones del legislador.

Dado el alto grado de indeterminación que caracteriza al lenguaje constitucional, particularmente en lo que a sus contenidos sustantivos se refiere, la tarea del Tribunal Constitucional trae consigo un amplio margen de discrecionalidad que es preciso justificar. En ese orden de ideas, la búsqueda de herramientas argumentativas que logren hacer que las decisiones del Tribunal Constitucional resulten comprensibles y aceptables para los ciudadanos se convierte en tarea prioritaria para una teoría constitucional que, desde una perspectiva constructiva, pretenda aportar elementos para mejorar la práctica del control de constitucionalidad de las leyes.

Una de estas herramientas argumentativas, que ha gozado de especial predicamento entre la teoría y la práctica constitucional en las dos últimas décadas, es el llamado principio de proporcionalidad, en virtud del cual una medida que afecta un derecho fundamental (o algún otro contenido constitucional susceptible de operar como principio) sólo es válida a condición de que sea idónea para contribuir al logro de un fin legítimo (constitucionalmente justificado); necesaria, en tanto no existan alternativas que permitan lograr el mismo fin con un menor sacrificio para los principios constitucionales afectados

${ }^{1}$ Al respecto vid. Ferreres Comella, V., Justicia constitucional y democracia, Madrid, Centro de Estudios Políticos y Constitucionales, 1997 (2a . ed., 2007); del mismo autor, "El control judicial de la constitucionalidad de la ley. El problema de su legitimidad democrática”, en M. Carbonell y L. García Jaramillo (edits.), El canon neoconstitucional, Bogotá, Universidad Externado de Colombia, 2010, pp. 477-503. 
por la medida enjuiciada; finalmente, que ésta sea proporcional en sentido estricto, lo que ocurrirá cuando los beneficios que la medida reporta, en términos de contribución al logro de un fin constitucionalmente justificado, compensen los sacrificios que aquella representa para los derechos fundamentales u otros principios constitucionales afectados con la medida enjuiciada.

Existe un número significativo de trabajos que exploran la función del principio de proporcionalidad en la argumentación constitucional, ofrecen desarrollos minuciosos de cada uno de los subprincipios que lo componen o destacan las falencias de racionalidad que aquejan a dicha estructura argumentativa ${ }^{2}$. Otros exploran sus posibilidades y límites como instrumento de control de las intervenciones en derechos fundamentales que tienen lugar en diversos sectores del ordenamiento jurídico, entre ellos el derecho penal. En este ámbito, se ha reflexionado sobre los contenidos específicos y de los límites de racionalidad que aquejan al principio de proporcionalidad cuando se proyecta en el control de constitucionalidad de las leyes que definen los delitos y las penas ${ }^{3}$.

En este artículo propongo una aproximación a la manera en que el principio de proporcionalidad ha sido utilizado en el control de las leyes penales en la jurisprudencia del Tribunal Constitucional chileno y de la Corte Constitucional colombiana, con el fin de indagar en qué medida tal herramienta ha contribuido al propósito de elevar la racionalidad de las decisiones relativas al control de las decisiones político criminales del legislador. Para ello pretendo examinar las diferencias que median entre ambos sistemas de justicia constitucional para, sobre esta base, indagar si en qué medida y en qué ocasiones los tribunales constitucionales chileno y colombiano han formulado las

${ }^{2}$ Entre la bibliografía disponible en español valga mencionar, entre otros, los trabajos de Alexy, R. Teoría de los derechos fundamentales (1986), trad. E. Garzón Valdés, $1^{\text {a }}$ ed. en castellano, 2a reimp., Madrid, CEPC, 2001; del mismo, "Epílogo a la Teoría de los Derechos Fundamentales", trad. C. Bernal, Revista Española de Derecho Constitucional, 66, 2002, pp. 13-64; Bernal Pulido, C., El principio de proporcionalidad y los derechos fundamentales, $2^{a}$. ed., Madrid, CEPC, 2005; Clérico, L., El examen de proporcionalidad en el derecho constitucional, Buenos Aires, EUDEBA, 2009, 408 p.; los trabajos incluidos en el volumen colectivo El principio de proporcionalidad en el estado constitucional, M. Carbonell (coord.), Bogotá, Universidad Externado de Colombia, 2007, 340 p. también editado en Chile bajo el título El principio de proporcionalidad en la interpretación jurídica, M. Carbonell (coord.), Santiago, Librotecnia, 2010, 412 p.

3 Vid., entre otros, los trabajos de Aguado Correa, T., El principio de proporcionalidad en derecho penal, Madrid, EDERSA, 1999; Cuerda Arnau, M. L., "Aproximación al principio de proporcionalidad en derecho penal”, en Estudios jurídicos en memoria del profesor Dr. D. José Ramón Casabó Ruiz, Valencia, Universitat - Instituto de Criminología, 1997, pp. 447-491; Fernández Cruz, J. A., "El juicio constitucional de proporcionalidad de las leyes penales: la legitimación democrática como medio para mitigar su inherente irracionalidad", Revista de Derecho Universidad Católica del Norte, Año 17, No. 1, 2010, pp. 51-99; Lascuraín Sánchez, J. A., "La proporcionalidad de la norma penal". Cuadernos de Derecho Público, 5, 1998, pp. 159-189; Lopera Mesa, G.P., Principio de proporcionalidad y ley penal, Madrid, Centro de Estudios Políticos y Constitucionales, 2006, 661 p.; Mata Barranco, Norberto de la, El principio de proporcionalidad penal, Valencia, Tirant Lo Blanch, 2007, 331 p.; Mir Puig, S., "Principio de proporcionalidad y fines del derecho penal", en: J. I. Echano Basaldúa (edit.), Estudios en memoria de José María Lidón. Bilbao, Universidad de Deusto, 2002, pp. 349-366; Mir Puig, S., "El principio de proporcionalidad como fundamento constitucional de límites materiales del Derecho Penal”, en: J. C. Carbonell Mateu, J.L. González Cussac, E. Orts Berenguer (Dir.), Constitución, Derechos Fundamentales y Sistema Penal (Semblanzas y estudios con motivo del setenta aniversario del profesor Tomás Salvador Vives Antón), Tomo II, Valencia, Tirant Lo Blanch, 2009, pp. 1357-1382. 
preguntas e incorporado las exigencias que reclama la aplicación de aquella herramienta argumentativa en el control constitucional de las leyes penales sustantivas.

\section{La deferencia hacia el legislador penal del Tribunal CONSTITUCiOnAL CHILENO}

Para examinar la manera en que el Tribunal Constitucional chileno ha incorporado el principio de proporcionalidad en el control de constitucionalidad de las leyes penales tendré en cuenta tres aspectos: en primer lugar, la discusión sobre los fundamentos constitucionales que avalan el empleo de dicha estructura argumentativa en el control de constitucionalidad de las leyes; en segundo lugar, el examen de los casos en los que el Tribunal Constitucional ha empleado argumentos de proporcionalidad en el control de normas penales; finalmente, el alcance conferido a esta herramienta de control.

1.1. Aunque en línea de principio, parecería existir consenso entre los Ministros del Tribunal sobre la pertinencia de emplear el principio de proporcionalidad en el control de constitucionalidad de las leyes que afectan derechos fundamentales ${ }^{4}$; existen discrepancias sobre su fundamentación positiva, ya que la Constitución chilena no consagra de manera expresa la exigencia de que toda intervención en derechos fundamentales venga sometida a la exigencia de proporcionalidad en sentido amplio, como tampoco establece de manera expresa la exigencia de proporcionalidad de las penas, esto es, de correspondencia entre la gravedad de la pena y del delito. En algunas de las sentencias en las que se examina la constitucionalidad de normas penales, el Tribunal ha establecido un vínculo entre la exigencia de proporcionalidad y la prohibición de establecer diferencias arbitrarias (art. 19, inc. $2^{\circ}$. C.Chil.) $)^{5}$. Sin embargo, estos pronunciamientos han contado con el voto en contra de algunos Ministros que consideran más acertado adscribir el principio de proporcionalidad (refiriéndose con esta expresión tanto a la proporcionalidad en sentido amplio como a la proporcionalidad de las penas) al principio que garantiza el justo y debido proceso en lugar de interpretarlo como correlato del principio de igualdad ${ }^{6}$. Entre tanto, en las sentencias en las que se examina la constitucionalidad

\footnotetext{
${ }^{4}$ En efecto, varias sentencias retoman las consideraciones efectuadas en fallos precedentes, en particular la sentencia Rol No. 519-2006 (constitucionalidad del apremio con arresto al empleador que no consigne las sumas descontadas a los trabajadores por concepto de cotizaciones a la seguridad social), en cuyo considerando $19^{\circ}$ se afirma la necesidad de que toda intervención en derechos fundamentales respete las exigencias de necesidad y proporcionalidad. En esta decisión se retoman, a su vez, consideraciones efectuadas en las sentencias Rol No. 226 (inconstitucionalidad de algunas normas del proyecto de ley sobre "libertad de expresión, información y ejercicio del periodismo"), No. 280 (constitucionalidad de aumento de impuestos a la gasolina y el tabaco).

${ }^{5}$ Así ocurre en las sentencias Rol 787-07, 797-07, 825-07 y 829-07 (constitucionalidad del artículo 450 CP). A favor de esta fundamentación vid. Fernández Cruz, J. A., "El juicio constitucional de proporcionalidad de las leyes penales: la legitimación democrática como medio para mitigar su inherente irracionalidad", Revista de Derecho Universidad Católica del Norte, Año 17, No. 1, 2010, p. 56.

${ }^{6}$ En tal sentido se pronuncian los ministros Mario Fernández Baeza y Hernán Vodanovic en los votos en contra a las sentencias Rol 787-07, 797-07, 825-07 y 829-07 (constitucionalidad del artículo 450 CP).
} 
de normas que establecen el arresto como mecanismo de apremio, se ha fundamentado la exigencia de proporcionalidad en la prohibición de imponer apremios ilegítimos (art. 19.1 C.Chil.) ${ }^{7}$. Además de los fundamentos anteriores, la doctrina ha vinculado el principio de proporcionalidad con la garantía genérica de los derechos y la prohibición de alterar el contenido esencial de los derechos fundamentales (arts. 5 y 19.26 C.Chil.) ${ }^{8}$, el principio democrático, el valor justicia y la dignidad humana?

1.2. Para examinar los casos en los que esta herramienta argumentativa ha sido empleada en el control de constitucionalidad de las leyes penales es preciso tener en cuenta que, en lo que atañe específicamente al control de constitucionalidad de las leyes, el Tribunal Constitucional chileno ejerce su labor fiscalizadora a través de tres mecanismos principales ${ }^{10}$ : La acción de inaplicabilidad por inconstitucionalidad, un mecanismo de control en concreto de las leyes y con efectos inter partes, que efectúa el Tribunal Constitucional a solicitud de las partes o del órgano de la jurisdicción ordinaria encargado de tramitar el caso dentro del cual se origina la cuestión de inconstitucionalidad. En segundo lugar, la declaración de inconstitucionalidad en abstracto, que se introdujo tras la reforma constitucional de 2005, posibilita el control posterior, con efectos erga omnes y no retroactivos ${ }^{11}$, respecto de preceptos legales que antes hayan sido declarados inaplicables a un caso concreto. Este mecanismo de control puede ser activado de oficio, por el propio Tribunal Constitucional, o a petición ya no sólo de los mismos sujetos legitimados para solicitar la inaplicabilidad sino de cualquier otra persona, constituyéndose de este modo en una acción pública. Finalmente, el control previo de proyectos de ley que el Tribunal realiza de oficio y con carácter obligatorio respecto de leyes interpretativas de la Constitución, leyes orgánicas constitucionales y tratados internacionales sometidos a la aprobación del Congreso. También pueden ser objeto de control previo otros proyectos de ley, pero

${ }^{7}$ Vid. Prevención a la sentencia Rol 1145-08, suscrita por los Ministros Jorge Correa Sutil y Raúl Bertelsen Repetto.

${ }^{8}$ Vid. Nogueira Alcalá, H., "El derecho de igualdad ante la ley, la no discriminación y acciones positivas", Anuario da Facultad de Direito da Universidade da Coruña (AFDUC), 10, 2009, p. 812; Nogueira Alcalá, H., "El principio de proporcionalidad y su aplicación en Sudamérica por la jurisdicción constitucional, con especial mención al Tribunal Constitucional chileno", en Carbonell, M. (coord..), El principio de proporcionalidad en la interpretación jurídica, Santiago, Librotecnia, 2010 (las referencias a este texto corresponden al manuscrito original, que el autor de manera amable me facilitó); Fuentes Cubillos, H., "El principio de proporcionalidad en Derecho Penal. Algunas consideraciones acerca de su concretización en el ámbito de la individualización de la pena", Ius et Praxis, Vol. 14, No. 2, 2008, p. 13.

${ }^{9}$ Para una síntesis de las posiciones doctrinales sobre el tema, vid. Saona Marín, T., La aplicación del principio de proporcionalidad por el Tribunal Constitucional chileno en el control constitucional de normas penales. Memoria para optar al grado de Licenciado en Ciencias Jurídicas y Sociales, Valdivia, Universidad Austral, 2010 , p. 20 y ss.

${ }^{10}$ El sistema constitucional chileno no concentra en exclusiva el control de constitucionalidad en el Tribunal Constitucional, pues también entrega competencias de control a las Cortes de Apelaciones y a la Corte Suprema, por medio del recurso de protección.

${ }^{11}$ Para un examen de los efectos temporales de las sentencias de constitucionalidad en materia penal, véase Caballero Brun, F., "Derecho Penal sustantivo y efectos en el tiempo de la sentencia del Tribunal Constitucional que declara la inconstitucionalidad de un precepto penal”, en Revista de Derecho (Valdivia), vol. XIX, 2006, pp. 161-185. 
en este caso a solicitud de los órganos constitucionalmente legitimados (Presidente de la República, de las Cámaras o de una parte de sus miembros).

A diferencia de lo que ocurre en Colombia, donde el control abstracto de constitucionalidad ocupa un lugar predominante, en Chile la gran mayoría de las cuestiones de las que se ocupa el Tribunal llegan a través del control en concreto que se realiza a través del recurso de inaplicabilidad por inconstitucionalidad. Al respecto señala José Ángel Fernández que, tras la reforma constitucional de 2005, la única cuestión constitucional en materia penal de la que se ha ocupado el Tribunal a través de los mecanismos de control en abstracto ha sido la contenida en la sentencia Rol No. 786-07, del 13 de junio de 2007, que resuelve el requerimiento de inconstitucionalidad del proyecto de ley modificatorio del sistema de responsabilidad penal adolescente ${ }^{12}$. El artículo $3^{\circ}$ de este proyecto establecía el internamiento en régimen cerrado como única modalidad de ejecución de las sanciones superiores a cinco años, modificando así la norma que permitía al juez optar por un régimen semicerrado o cerrado de internación. El Tribunal Constitucional desestimó el requerimiento de inconstitucionalidad, por considerar que la determinación de las penas y de sus modalidades de cumplimiento es un asunto que compete en exclusiva al legislador, respecto de las cuales el Tribunal ha de limitarse a verificar que las penas persigan fines constitucionalmente lícitos y no vulneren los límites precisos impuestos por la Constitución, como son la prohibición de establecer apremios ilegítimos, sancionar con la confiscación de bienes o la pérdida de derechos previsionales y respetar los derechos esenciales del ser humano (F.J. $30^{\circ}$ ). En este caso el Tribunal se limita a afirmar, sin ofrecer fundamento alguno, que la medida cuestionada no trasgrede los límites anteriores (F.J. $32^{\circ}$ ). Sin embargo, en el voto en contra suscrito por el Ministro Hernán Vodanovic Schnake se efectúan consideraciones sobre falta de idoneidad de la medida de internamiento en régimen cerrado para alcanzar el fin resocializador del menor y la falta de necesidad de acudir a la privación de libertad, ante la existencia de otras alternativas (considerando $10^{\circ}$ ).

Tal actitud de extrema deferencia hacia las decisiones del legislador penal, al punto de inhibir su competencia de control, es mantenida por el Tribunal Constitucional chileno incluso en las cuestiones en las que no se discute la constitucionalidad en abstracto de las normas penales, sino su aplicación a los casos concretos, como veremos a continuación:

12 Fernández Cruz, J. A., "El juicio constitucional de proporcionalidad de las leyes penales: la legitimación democrática como medio para mitigar su inherente irracionalidad”, citado, p. 68 (nota 67). Este autor sugiere que, para el caso de las leyes penales, la prevalencia del recurso de inaplicabilidad sobre los restantes mecanismos de control constitucional obedece no tanto a su carácter concreto, sino más bien a que el modelo penal de seguridad ciudadana sólo ha encontrado resistencia en algunos sectores del Poder Judicial y de la Defensoría Penal Pública. Entre tanto, en una investigación reciente, Tamara Saona sostiene que no existen antecedentes de declaración de inconstitucionalidad de normas penales a través del recurso abstracto de constitucionalidad. Saona Marín, T., La aplicación del principio de proporcionalidad por el Tribunal Constitucional chileno en el control constitucional de normas penales, citado, p. 24 (nota 99). 
a) Imposición de la pena prevista para el delito consumado, en ciertos supuestos de tentativa o delito frustrado de robo

El artículo 450, inciso $1^{\circ}$, del C. P. chileno ordena castigar con la misma pena para el delito consumado a los hechos que constituyan tentativa o delito frustrado de robo con violencia o intimidación, robo con sorpresa, piratería, extorsión y robo con fuerza en las cosas en lugar habitado o destinado a la habitación. La constitucionalidad de esta norma ha sido cuestionada en reiteradas ocasiones por los tribunales de instancia, invocando, entre otros argumentos, la existencia de un trato desigual injustificado en relación con la disminución de pena establecida con carácter general para las modalidades imperfectas de ejecución de otros delitos, pero no reconocida en los supuestos establecidos en el artículo 450 C.P.

En las cuatro sentencias en las que el Tribunal Constitucional se ha pronunciado de fondo sobre esta cuestión, ha estimado que el legislador no impone una diferencia de trato injustificable al privar a las modalidades tentada y frustrada de los delitos establecidos en el artículo 450 C.P de la rebaja de pena establecida para las modalidades imperfectas de comisión de los demás delitos. En las dos primeras sentencias, el Tribunal cancela de plano toda posible discusión sobre la proporcionalidad del trato desigual, al descartar que esté en juego una infracción al principio de igualdad porque los supuestos que se comparan son distintos, razonamiento que envuelve una clara petición de principio ${ }^{13}$. En las sentencias posteriores llega a la misma conclusión, pero esta vez emplea una línea de argumentación que acoge una versión débil del principio de proporcionalidad ${ }^{14}$. Así, en las sentencia Rol 825-07 y 829-07, ambas del 6 de marzo de 2008, sostiene que la diferencia de trato establecida por el legislador persigue una finalidad lícita, puesto que no se basa en un criterio de discriminación constitucionalmente proscrito, sino que toma en cuenta una conducta voluntaria, como lo es la comisión de determinados

${ }^{13}$ Así lo afirma en los F.J. 19 y 20 de la sentencia Rol 787-07, de 18 de diciembre de 2007, reiterados de idéntica forma en la sentencia Rol 797-07, del 24 de enero de 2008, donde sostiene que "la igualdad ante la ley consiste en que las normas jurídicas deben ser iguales para todas las personas que se encuentren en las mismas circunstancias y, consecuentemente, diversas para aquellas que se encuentren en situaciones diferentes". Sobre esta base, concluye que en el supuesto planteado no existe vulneración de este mandato, por cuanto "la calidad de las personas que se encuentran en las mismas circunstancias la constituyen aquellas acusadas de cometer en grado de tentativa o frustración algunos de los tipos señalados en el artículo 450 del Código Penal y no las que han cometido otros ilícitos en etapa imperfecta de desarrollo y que en virtud de ello pueden ser beneficiadas en los artículos 51 y siguientes del mismo Código”. Es fácil advertir la petición de principio presente en este razonamiento, pues lo que estaba precisamente en discusión era la constitucionalidad de la diferenciación establecida por el legislador en el artículo 450 del C.P, respecto al trato dispensado a las modalidades imperfectas de comisión de otros delitos. En otras palabras, el Tribunal señala que la distinción establecida por el legislador en el artículo 450 C.P. no es contraria al principio de igualdad, porque los supuestos con los que se plantea la comparación son diferentes, precisamente en virtud de la distinción establecida por el legislador en el artículo 450 del C.P.

${ }^{14}$ De este modo, el Tribunal acoge la fundamentación propuesta en la aclaración de voto (prevenciones) a las sentencias Rol 787-07 y 797-07, por los Ministros Raúl Bertelsen Repetto, Jorge Correa Sutil, Marisol Peña y Francisco Fernández Fredes. 
delitos contra la propiedad, cuya ocurrencia el legislador intenta prevenir a través de un trato punitivo más severo (F.J. $19^{\circ}$ y $20^{\circ}$ ). A continuación, el Tribunal emplea una versión débil del juicio de idoneidad para avalar la idoneidad del medio empleado por el legislador y declara su incompetencia para entrar a examinar la necesidad del medio, argumentando que:

"...el legislador, para conseguir el abatimiento de ciertos ilícitos, escoge privar a los responsables de ellos de la disminución de las penas que generalmente reconoce a los que quedan en grado de tentativa o frustración. Podrá dudarse si el medio empleado es el más adecuado o idóneo. Podrá discutirse si no habrá otros más aptos para alcanzar igual finalidad, pero no es irracional y se encuentra dentro de los márgenes de estimación propios del legislador suponer que logrará disminuir la frecuencia de ciertos delitos al privar a los responsables de aquellos que no alcanzan a consumarse de un beneficio que asigna para los restantes casos. A esta Magistratura no le corresponde sustituir el juicio propio del legislador, ni juzgar la sabiduría o mérito de los instrumentos que emplea, incluso si ellos conllevan diferencias, a condición de que estos instrumentos diferenciadores se presenten como razonablemente idóneos para alcanzar fines constitucionalmente lícitos y se dé la proporcionalidad que se apreciará en el considerando que sigue" (F.J. 21%).

Proporcionalidad que examina también desde una perspectiva débil, al señalar que el trato desigual establecido por el legislador al excluir la rebaja de penas para el grado de tentativa o el delito frustrado en los supuestos de robo previstos en el artículo 450 del C. P. chileno no puede considerarse "tan desproporcionado" como para incurrir en infracción a la norma constitucional del art. 19.2 que prohíbe al legislador establecer diferencias arbitrarias (F. J. $22^{\circ}$ ). Sin embargo, el Tribunal no ofrece argumentos adicionales que sustenten esta conclusión.

Fundamentación que resultaba aún más necesaria teniendo en cuenta los argumentos expuestos en los dos votos en contra. En uno de ellos, suscrito por Teodoro Ribera Neumann, se afirma la falta de idoneidad de sancionar la tentativa con la misma pena del delito consumado, por cuanto tal medida puede conducir a un resultado adverso al que se pretende alcanzar, al privar a quien ha iniciado la comisión del delito de una razón para detenerse en su ejecución y abstenerse de consumarlo. Por su parte, en el voto en contra suscrito por los ministros Mario Fernández Baeza y Hernán Vodanovic Schnake, se cuestiona la necesidad de la medida, en tanto la prevención de delitos se pretende alcanzar sólo a través del endurecimiento de penas, sin adoptar medidas complementarias que hagan posible la rehabilitación y resocialización de los sancionados.

Los votos en disidencia ponen de manifiesto que en esta ocasión se presentó un interesante debate al interior del Tribunal ya no sólo sobre la fundamentación positiva, sino sobre el alcance y la intensidad con la que ha de ser aplicado cada uno de los subprincipios de la proporcionalidad. Ello reclamaba del voto mayoritario una respuesta razonada a los argumentos presentados por los ministros disidentes en contra de la idoneidad y necesidad de la medida enjuiciada, como condición para que el uso de dicha 
estructura argumentativa realmente sirva a su finalidad de incrementar la racionalidad de la argumentación constitucional.

\section{b) Inbabilitación especial perpetua en delitos de fraude al fisco}

En la sentencia Rol 1328-09, de 6 de agosto de 2009, el Tribunal resuelve un recurso de inaplicabilidad de la pena de inhabilitación especial perpetua para el cargo u oficio público, que se impone a los condenados por el delito de fraude al fisco (art. 239 C.P. Chil.). Quien eleva el recurso argumenta que tal sanción es contraria al artículo 17.2 de la Constitución chilena, el cual establece la pérdida de ciudadanía sólo para los supuestos en que se imponga "pena aflictiva", lo cual no ocurre en este caso, pues el delito de fraude al fisco tiene prevista una pena de reclusión menor, no comprendida dentro del tipo de sanciones que el artículo 37 del C. P. chileno define como "penas aflictivas". Por tal razón, sostiene el requirente, resulta inconstitucional sancionar el delito de fraude al fisco con una pena que comporta la privación de derechos directamente relacionados con el ejercicio de la ciudadanía, como ocurre en el caso objeto de controversia, en donde el procesado podría ser sancionado con inhabilitación perpetua para ejercer los cargos de alcalde, diputado o senador ${ }^{15}$. Finalmente, el peticionario sostiene que el carácter perpetuo de la pena que se pretende imponer al procesado resulta incompatible con la posibilidad de que incluso los condenados a pena aflictiva obtengan la rehabilitación de la ciudadanía, según lo dispuesto en el artículo 17 de la Constitución chilena.

En la decisión de este recurso se plantearon dos votos en sentido contrario: uno acogía y otro rechazaba el recurso. El empate fue dirimido por el Ministro Presidente del Tribunal, quien se inclinó por la tesis que desestimaba el recurso de inaplicabilidad, por considerar, entre otras razones, que la inhabilitación especial constituye una pena aflictiva, de acuerdo con la clasificación efectuada por el legislador, y que no equivale a una pérdida de la ciudadanía, pues tan sólo comporta la privación del derecho a ocupar determinados cargos públicos. En uno de los considerandos de la sentencia que acoge el voto desestimatorio, se alude a la exigencia de proporcionalidad de las penas, con el fin de ratificar la deferencia hacia el legislador que mantiene el Tribunal Constitucional chileno, al considerar que "hay penas distintas para cada delito e incluso puede haber penas más altas para delitos que nos pueden parecer menos graves. La decisión es del legislador" (F.J. 13º). En definitiva, de acuerdo con la postura que el Tribunal Constitucional chileno plasma en esta decisión, la libertad de configuración legislativa en materia penal no encontraría límite alguno en la exigencia de proporcionalidad entre pena y delito.

${ }^{15}$ Cabe señalar que el artículo 239 del C. P. chileno fue reformado mediante la Ley $\mathrm{N}^{\circ} 20.341$, con posterioridad a que se planteara el recurso de inaplicabilidad por inconstitucionalidad, pero antes de que fuese proferida la sentencia que lo resolvió. La nueva regulación reemplaza la pena de inhabilitación especial perpetua para el cargo u oficio desempeñado por el funcionario condenado, por la de inhabilitación absoluta para todos los cargos y oficios públicos, que deja de ser perpetua para tener una extensión de grado medio a máximo. 


\section{c) Actos de sodomía con varón menor de edad}

En sentencia reciente, Rol 1683-10, del 4 de enero de 2011, el Tribunal Constitucional resuelve un requerimiento de inaplicabilidad del artículo 365 del C. P. chileno, el cual penaliza a quien acceda carnalmente a joven mayor de 14 y menor de 18 años, con su consentimiento, sin que medien las circunstancias constitutivas de los delitos de violación o estupro. Entre otros argumentos, quien plantea el recurso sostiene que la norma establece una discriminación injustificada, al sancionar al varón que acceda carnalmente a una persona de su mismo sexo, mayor de 14 y menor de 18 años, aun cuando la relación sexual sea libremente consentida, lo que contrasta el tratamiento dispensado a las relaciones sexuales libremente consentidas entre un hombre y una mujer, cuando cualquiera de ellos sea mayor de 14 y menor de 18 años; entre dos mujeres, alguna de las cuales se ubique en esta franja etaria, o entre un hombre mayor de 18 y uno menor de esta edad y mayor de 14, cuando sea este último quien acceda carnalmente al otro.

El Tribunal Constitucional desestima el recurso, argumentando que el legislador no ha establecido una discriminación arbitraria o carente de razonabilidad, toda vez que, atendiendo al principio que ordena salvaguardar el interés superior del menor, busca "proteger a los menores de 14 y mayores de 14 años de edad que no gozan de la madurez suficiente para comprender los alcances y consecuencias en su propia vida de un 'acceso carnal' libremente consentido" (F.J. 33). Respecto a la desigualdad de trato con otros supuestos de relaciones sexuales consentidas con menores, el Tribunal desestima que se produzca un trato discriminatorio respecto de las relaciones entre mujeres al considerar que "la penalización del delito de sodomía no se debe a la inclinación sexual del agresor y de la víctima. Se debe al impacto que produce la penetración anal en el desarrollo psicosocial del menor varón, lo que no podría predicarse, en los mismos términos, de una relación entre mujeres en las mismas condiciones" (F.J. $33^{\circ}$ ). El Tribunal omite toda consideración sobre la discriminación que se produce respecto de los supuestos en los que el acceso carnal (sea anal o vaginal, para plantearlo en los términos de la distinción que el propio Tribunal juzga relevante establecer) se produce sobre mujer mayor de 14 y menor de 18 años $^{16}$.

Por último, el Tribunal considera que no existe vulneración del derecho a la privacidad ni de la libertad personal y dignidad humana, toda vez que, en el presente caso, la interferencia en el ámbito de intimidad y la restricción de libertad se justifica en virtud del principio que ordena proteger el interés superior del menor frente a conductas que pueden causarle un daño irreparable.

Esta sentencia fue acordada con voto en contra de los ministros Vodanovic Schnake, Carmona Santander, Viera-Gallo Quesney, quienes se manifestaron a favor de la inaplicabilidad del precepto. Tras refutar la finalidad atribuida a la norma por la decisión mayoritaria, el voto disidente sostiene que dicho precepto busca proteger a los jóvenes de la homosexualidad,

${ }^{16}$ La línea argumental que el Tribunal Constitucional chileno desarrolla en esta sentencia evoca el ancestral rechazo del Katapugon o Kinaidos, desde la Antigüedad hasta nuestros días, y elemento central para comprender la manera en que Occidente ha construido las relaciones entre sexo, género y poder. Vid. Allouch, J., El sexo del amo, Buenos Aires, El Cuenco de Plata, 2009, pp. 37 y ss. 
entendida como una práctica inherentemente lesiva, lo que pone de manifiesto un razonamiento homofóbico. Asimismo, el voto disidente plantea que las normas penales deben estar sujetas a un test más estricto de proporcionalidad, habida cuenta de la intensidad de la afectación en derechos que las mismas provoca. Este escrutinio estricto se justifica además, en este caso, en el que se establece una discriminación por razón del sexo y la orientación sexual de los intervinientes en el acto. Sin embargo, la línea argumentativa del voto disidente no desarrolla las exigencias derivadas de un test estricto de proporcionalidad, ni discurre conforme al derrotero trazado por dicha estructura argumentativa, para optar en su lugar por una detallada exposición del derecho comparado sobre el tema y de las razones por las cuales la norma, además de establecer una discriminación injustificada, vulnera los derechos a la privacidad y a la libertad sexual. No obstante, en algunos apartes se plantean argumentos relativos a la falta de idoneidad y necesidad de la norma impugnada. En tal sentido, los ministros disidentes sostienen que "la protección de los menores mediante el sometimiento a un proceso penal no es una vía idónea para garantizar su integridad sexual ni psíquica, ni para que desarrollen una sexualidad responsable. Existen otros medios menos lesivos que el derecho penal para dicho fin. Como es sabido, ser partícipe en un proceso penal, aun sin ser el imputado, puede resultar agresivo y perjudicial a los intereses del menor".

1.3. La anterior revisión jurisprudencial pone de manifiesto las discrepancias existentes al interior del Tribunal Constitucional chileno en torno a la utilización del principio de proporcionalidad en el control de normas penales. En la justificación de las decisiones mayoritarias dicha estructura argumentativa no es empleada en absoluto, o en las escasas ocasiones en que se hace mención de la proporcionalidad ésta se emplea como mera cláusula de estilo de la que no se extraen consecuencias para el control de constitucionalidad. En efecto, el Tribunal renuncia de manera expresa a efectuar algunos de los juicios que este incorpora, como el de necesidad, y los restantes subprincipios (idoneidad y proporcionalidad en sentido estricto) se aplican con un nivel mínimo de intensidad, al exigir que los medios punitivos empleados por el legislador resulten "razonablemente idóneos para alcanzar fines constitucionalmente lícitos" y el menoscabo para la libertad y otros derechos afectados no puede considerarse "tan desproporcionado" en relación con los fines que el legislador pretende alcanzar a través de las penas.

Este nivel mínimo de intensidad del control constitucional no resulta en sí mismo objetable, pues manifiesta una actitud de deferencia hacia las decisiones del legislador que, si bien implica un correlativo debilitamiento de la fuerza normativa de los derechos fundamentales, constituye la expresión de la manera en que la sociedad chilena ha construido el equilibrio institucional entre el poder legislativo y el Tribunal Constitucional y, en definitiva, la inevitable tensión que se plantea entre constitucionalismo y democracia. Equilibrio que, como veremos, se ha construido de modo muy distinto en el caso colombiano.

Lo que sí merece reparos es que tras la deferencia se agazape la pseudofundamentación, pues la legitimidad de los pronunciamientos del Tribunal Constitucional, sean estos favorables o no a las decisiones del legislador, depende, en definitiva, de la fuerza de los argumentos que los respaldan. No sólo hay que presentar argumentos sólidos cuando se declara la inconstitucionalidad o se ordena la inaplicación de un precepto legislativo. Esta exigencia argumentativa se mantiene cuando se trata de justificar ante la persona a quien 
se impondrá una pena y, en últimas, ante al conjunto de la sociedad, por qué la libertad y otros derechos fundamentales, pese a estar consagrados en la Constitución como límites al poder de las mayorías, pueden ser sacrificados por las decisiones político criminales adoptadas por estas mayorías y plasmadas en la ley penal.

El estilo argumentativo que presentan los votos de mayoría del Tribunal Constitucional chileno en las sentencias anteriormente examinadas, en particular la manera en que se ha valido del principio de proporcionalidad, no satisface exigencias elementales de racionalidad discursiva. Al margen de las críticas que puede merecer el recurso excesivo al argumento de autoridad, que se evidencia en las citas in extenso de textos constitucionales y legales, jurisprudencia y doctrina, que en largos tramos de los fundamentos jurídicos reemplazan la propia voz del Tribunal ${ }^{17}$, llama la atención que, en las sentencias en las que se ocupa del control de normas penales, la utilización selectiva y asistemática de algunos subprincipios de la proporcionalidad, en lugar de servir como insumo para incrementar la racionalidad de la fundamentación, se convierte en mampara retórica para evadir la exigencia de dar razones que avalen la constitucionalidad de las normas impugnadas.

Buen ejemplo de lo anterior lo constituye el recurso al principio de proporcionalidad en las sentencias Rol 825-07 y 829-07. Tienen razón quienes señalan que el empleo de dicha herramienta argumentativa en esta sentencias no corrige de manera significativa el déficit de fundamentación que se advierte en decisiones anteriores (Rol. 787-07 y 797-07), donde se aborda el examen de la constitucionalidad del trato desigual establecido por el legislador en el artículo 450 del C.P ${ }^{18}$. La petición de principio en la que incurre en estas dos últimas sentencias -no existe infracción al principio de igualdad porque los supuestos que se comparan son distintos, debido a la distinción efectuada por el legislador en la norma cuestionadase traslada ahora al razonamiento circular que acompaña la mención de la idoneidad y de la proporcionalidad en sentido estricto de la medida. En efecto, el Tribunal se limita a argumentar la idoneidad de la equiparación de las penas para el delito tentado y frustrado con la pena establecida para el delito consumado, señalando que no es irracional suponer que esta medida logrará disminuir la comisión de los delitos establecidos en el artículo 450 C.P., sin responder a los argumentos de los ministros que sostenían que tal equiparación de penas podría representar un mayor riesgo para los bienes jurídicos en juego y para las víctimas de este tipo de delitos. Más clara aún es la falta de fundamentación del requisito de la proporcionalidad en sentido estricto, que el Tribunal da por satisfecho al señalar que el tratamiento punitivo no es "tan desproporcionado". En definitiva, el Tribunal se vale del

17 Aspecto sobre el que llama la atención José Ángel Fernández, al cuestionar el excesivo recurso a las citas doctrinales y la falta de coherencia teórica entre muchas de ellas. Fernández Cruz, J. A., "El juicio constitucional de proporcionalidad de las leyes penales: la legitimación democrática como medio para mitigar su inherente irracionalidad", citado, p. 68 (nota 67).

${ }^{18}$ En tal sentido vid. Fernández Cruz, J. A., "La incorporación del juicio proporcionalidad en el control constitucional de las leyes penales: el recurso de inaplicabilidad del art. 450 inciso $1^{\circ}$ del Código Penal, rol 825”, ponencia en el Coloquio sobre Jurisprudencia Constitucional, Universidad Católica de Valparaíso, 9 y 10 de octubre de 2008 (ponencia pendiente de publicación, que cito gracias al manuscrito que me suministró el autor); Saona Marín, T., La aplicación del principio de proporcionalidad..., citado, pp. 33 y ss. 
principio de proporcionalidad para sostener que la medida enjuiciada es idónea porque no es irracional suponer que lo es y es proporcionada por cuanto no resulta "tan desproporcionada"19.

Este déficit de fundamentación contrasta con decisiones en las que el Tribunal Constitucional ha empleado el principio de proporcionalidad en el control de normas no penales, y en las que ha mostrado una mayor disposición a satisfacer las exigencias argumentativas que imponen los subprincipios de idoneidad, necesidad y estricta proporcionalidad, como es el caso de las sentencias Rol 1254-08 y Rol 1345-09, ambas proferidas por la mayoría calificada que se exige en el caso de la declaración de inconstitucionalidad de leyes con efectos generales $^{20}$. El contraste entre la fundamentación de estas sentencias y el de los pronunciamientos anteriormente examinados en materia penal pone en evidencia que las diferencias entre los votos de mayoría y los votos en contra que encontramos en las sentencias que se ocupan del control de las normas penales van más allá de una discusión entre estilos argumentativos más o menos proclives al uso de argumentos de proporcionalidad, para implicar en cambio discrepancias de fondo en torno a la concepción de los derechos fundamentales y su papel como límites al ejercicio del poder punitivo.

En efecto, la utilización del principio de proporcionalidad reclama una concepción de los derechos fundamentales como normas que, en los casos difíciles, imponen mandatos de optimización, esto es, ordenan que tales derechos sean garantizados en la mayor medida posible, y cuya limitación sólo es constitucionalmente legítima cuando las medidas que restringen el derecho constituyen medios idóneos, necesarios y estrictamente proporcionados para alcanzar alguna finalidad constitucionalmente legítima que entre en colisión con el principio que ordena la protección del derecho fundamental. Tal entendimiento de los

${ }^{19}$ Esta crítica a la deficiente utilización del principio de proporcionalidad en el control de normas penales es compartida no sólo en el círculo de la doctrina penal, sino también en el ámbito de la doctrina constitucional. Al respecto, el profesor Humberto Nogueira señala que "en diversas ocasiones el Tribunal Constitucional se queda en el análisis del fin constitucionalmente legítimo y el subprincipio de adecuación de medios al fin, sin realizar el control de la determinación de la existencia de otros medios igualmente idóneos para el logro del fin sin el sacrificio tan significativo del derecho restringido, como asimismo, no hay mucha argumentación sobre el principio de proporcionalidad en sentido estricto" (p. 19). En el caso específico de las normas penales, este autor advierte que "el Tribunal Constitucional no ha aplicado el test de proporcionalidad completo especialmente en materia de disposiciones legislativas penales, donde ha dejado al legislador un amplio margen de libertad, el cual no ha sido contenido aplicando el subprincipio de necesidad o intervención mínima respecto de los derechos" (p. 29), Nogueira Alcalá, H., "El principio de proporcionalidad y su aplicación en Sudamérica...”, citado, pp. 19 y 29.

${ }^{20}$ En la primera se declara la inconstitucionalidad con efectos erga omnes de la expresión "gratuitamente", contenida en el artículo 595 del Código Orgánico de Tribunales, en virtud de la cual se imponía a los abogados la obligación de cumplir de manera gratuita con el cargo de abogado de turno. En esta ocasión, el Tribunal sostiene que el medio empleado por el legislador es innecesario, por cuanto existe la alternativa de establecer un sistema de remuneración a los abogados que asumen la representación de personas de escasos recursos. Entretanto, en la sentencia Rol. 1345-09 se declara la inconstitucionalidad, también con efectos erga omnes, de la norma contenida en el artículo 171 del Código Sanitario, que imponía la obligación de cancelar las multas como condición para admitir el recurso de apelación en contra de medidas administrativas sancionatorias. El Tribunal considera que se trata de una afectación irrazonable del derecho de acceso a la administración de justicia, debido a su carácter innecesario y desproporcionado, en tanto la propia legislación sanitaria consagra otros mecanismos para lograr el fin de evitar litigios frívolos. Por su parte, la prevención suscrita por el Ministro Enrique Navarro Beltrán cuestiona incluso la idoneidad de la medida para alcanzar dicha finalidad. 
derechos fundamentales implica concebirlos como límite a todo ejercicio del poder estatal, incluidas las decisiones político criminales del legislador, en tanto a través de ellas el Estado define las condiciones bajo las cuales ha de emplear el más drástico mecanismo de intervención en la libertad y otros derechos fundamentales de las personas.

La revisión de las sentencias en las que el Tribunal Constitucional chileno se ha ocupado de examinar la constitucionalidad de normas penales permite concluir que un sector mayoritario de los integrantes del Tribunal no participa de la concepción de los derechos fundamentales anteriormente expuesta, ni los concibe como límites a las decisiones político criminales del legislador, o al menos no está dispuesto a extraer consecuencias prácticas de tal reconocimiento. Así lo evidencia la tesis dominante en el Tribunal, que reconoce una amplia libertad de configuración legislativa en materia político criminal, sólo limitada por las exigencias derivadas del principio de humanidad, la prohibición de tortura y penas o tratos crueles, inhumanos o degradantes y el mandato de respetar condiciones de dignidad en la ejecución de las penas ${ }^{21}$. Desde esta perspectiva, la exigencia de no establecer limitaciones desproporcionadas a la libertad y demás derechos fundamentales que se ven afectados por la definición legislativa de delitos y penas, pese a las declaraciones en sentido contrario, hasta el presente no ha sido incluida dentro del parámetro de constitucionalidad que el Tribunal Constitucional chileno emplea cuando examina la constitucionalidad de las normas penales.

\section{LA UTILIZACIÓN SELECTIVA DEL PRINCIPIO DE PROPORCIONALIDAD EN LA JURISPRUDENCIA CONSTITUCIONAL COLOMBIANA}

Aunque con diferencias apreciables en relación con el diseño institucional chileno, también en Colombia existe un sistema mixto de control de constitucionalidad que combina mecanismos de control en abstracto y en concreto. En el caso de las leyes, el control abstracto de constitucionalidad lo ejerce la Corte Constitucional, principalmente a través de la acción pública de inconstitucionalidad, la cual faculta a cualquier ciudadano para pedir a la Corte que declare la inexequibilidad (inconstitucionalidad) con efectos erga omnes de normas contenidas en leyes y algunos decretos con fuerza de ley ${ }^{22}$. Por su parte, el control de la constitucionalidad en concreto opera a través de dos mecanismos: la excepción de inconstitucionalidad, que faculta a autoridades judiciales y administrativas para inaplicar, con efectos inter partes, aquellas normas manifiestamente incompatibles con la Constitución. También la acción de tutela opera como un mecanismo de control de constitucionalidad difuso y en concreto, en tanto permite a cualquier juez inaplicar

${ }^{21}$ Tesis que se expone, entre otras, en los considerandos de las sentencias Rol No. 825-07, 829-07 (art. 450 CP) y 1328-09 (Pena de inhabilitación especial para delitos de fraude al fisco).

22 Además de la acción pública, que establece un control posterior de constitucionalidad, existen mecanismos de control previo, que operan para determinados proyectos de ley o de reforma constitucional (art. 241 C.Col.). Por su parte, el control de constitucionalidad en abstracto de la mayoría de los decretos es ejercido por la jurisdicción contencioso administrativa, cuyo máximo tribunal es el Consejo de Estado (art. 237 C.Col.). 
una disposición legal cuando ella comporte la vulneración de derechos fundamentales en un caso específico.

Pero a diferencia de lo que ocurre en Chile, en el caso colombiano la jurisprudencia emitida en ejercicio del control de constitucionalidad en abstracto ocupa un volumen y ostenta una importancia considerable. Sin duda el carácter difuso del control de constitucionalidad en concreto, sumado al dinamismo e importancia adquirida por la jurisprudencia de la Corte Constitucional en el sistema de fuentes, ha llevado a que las discusiones de constitucionalidad en abstracto que tienen lugar ante la Corte Constitucional desplacen significativamente la figura de la excepción de inconstitucionalidad de las leyes.

A continuación abordaré tres perspectivas de análisis de la manera en que la Corte colombiana ha empleado el principio de proporcionalidad en el control de las leyes penales sustantivas: cualitativa, examinando de qué manera se han concretado las exigencias de legitimidad del fin, idoneidad, necesidad y proporcionalidad en sentido estricto, cuando se proyectan sobre el control de constitucionalidad de las leyes penales; cuantitativa, tratando de mirar en cifras qué tan representativa es la utilización del PP

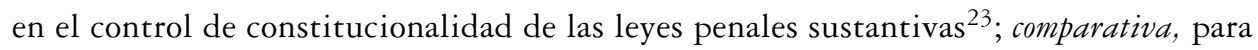
tratar de establecer en qué casos se emplea y en qué casos se elude la utilización de esta herramienta. Finalmente, a modo de conclusión, señalo algunas tendencias generales que se aprecian en la utilización o no utilización de esta herramienta por parte de la jurisprudencia constitucional colombiana.

\subsection{Perspectiva cualitativa}

Desde el comienzo de su labor, la Corte Constitucional colombiana ha empleado el principio de proporcionalidad como herramienta para evaluar la legitimidad constitucional de las medidas restrictivas de derechos fundamentales. En su jurisprudencia temprana, tal principio fue empleado casi exclusivamente en la aplicación del principio de igualdad, como uno de los componentes del llamado "test de razonabilidad", pero progresivamente se extendió al enjuiciamiento -tanto en sede de control abstracto de constitucionalidad como de tutelas- de otro tipo de medidas restrictivas de derechos

${ }^{23}$ Debido a la gran cantidad de sentencias de constitucionalidad en materia penal sustantiva, para la elaboración de este trabajo limité la búsqueda a las sentencias proferidas en los últimos 10 años con ocasión del control de constitucionalidad de las normas del Código Penal. El límite temporal no es caprichoso, pues coincide con la expedición del actual Código Penal, que luego ha sido acompañado por una avalancha de legislación complementaria cuya tendencia, en líneas muy gruesas, viene a plasmar la política de "seguridad democrática" que ha marcado el rumbo de las reformas penales en buena parte de la última década. Para este análisis cuantitativo excluiré el estudio de las sentencias que examinan la constitucionalidad de normas en materia procesal penal, en las que se han producido algunas decisiones importantes fundamentadas con ayuda del principio de proporcionalidad. También excluyo una revisión sistemática de las sentencias que examinan la constitucionalidad de la legislación penal complementaria, a las cuales se hará alusión sólo de manera episódica. 
fundamentales proferidas por los poderes públicos, al igual que a la resolución de colisiones de derechos fundamentales en el ámbito de las relaciones entre particulares.

En el desarrollo temprano de esta herramienta argumentativa se advierte, por un lado, la influencia de la doctrina jurídica alemana y de la jurisprudencia del Tribunal Europeo de Derechos Humanos, de la cual la Corte retoma las etapas que integran el juicio de proporcionalidad: (1) idoneidad para contribuir al logro de un fin constitucionalmente válido; (2) necesidad, entendida como la no existencia de un medio menos oneroso, en términos del sacrificio de otros principios constitucionales, para alcanzar el fin; y (3) proporcionalidad en sentido estricto. Igualmente, se aprecia la influencia de la jurisprudencia estadounidense, en particular en el intento por establecer distintos niveles de intensidad en el escrutinio, en función del tipo de medida de cuya evaluación se trata (siendo más débil el escrutinio en aquellos ámbitos donde se reconoce una libertad de configuración más amplia al legislador), del criterio de diferenciación empleado (cuando se trata de medidas que comprometen el principio de igualdad) y del derecho fundamental en juego (en general para medidas que afectan la libertad de expresión se emplea un test estricto). La Corte ha reconocido de manera expresa esta doble influencia y ha intentado integrar ambos modelos en el que denomina "juicio integrado" de igualdad (también denominado "juicio integrado de proporcionalidad), cuyos elementos principales define en la sentencia C-093/2001 (M.P. A. Martínez Caballero) ${ }^{24}$ y desde entonces ha desarrollado en decisiones posteriores. Las principales diferencias radican en el nivel de intensidad con el que se aplican los criterios de legitimidad del fin, adecuación, necesidad y proporcionalidad en sentido estricto, reservándose esta última etapa del test sólo para la aplicación del test estricto.

En las sentencias relativas al control constitucional de normas penales sustantivas no suele aparecer una referencia expresa a la diferencia de niveles de escrutinio. Simplemente, sobre la base de admitir que el legislador ostenta una amplia libertad de configuración en material penal, que sólo permite excluir aquellas medidas cuya falta de "razonabilidad y proporcionalidad" sea manifiesta, de entrada el escrutinio de medidas penales se sitúa en el nivel más débil. Dentro de la jurisprudencia revisada solo aparecen dos excepciones a esta tendencia, en sentencias recientes que involucraban medidas penales que restringían la libertad de expresión y en las que expresamente se anuncia la aplicación de un test estricto de proporcionalidad. La primera de ellas es la C-417/2009 (M.P. J.C. Henao Pérez), en la que se declara inexequible la norma que impedía aplicar la exceptio veritatis para el delito de calumnia cuando existiera sentencia absolutoria u otro pronunciamiento judicial de fondo que exonerara de responsabilidad al calumniado; en este caso, la Corte fundamentó la aplicación del test estricto en el carácter preferente de la libertad de expresión.

La segunda es la sentencia C-575/2009 (M.P. H. Sierra Porto), en la que se declara la inconstitucionalidad del delito de ultraje a símbolos patrios y en la cual, como fundamento para aplicar un test de proporcionalidad estricto, se aduce no solo el estar

\footnotetext{
${ }^{24}$ En la cual se declara exequible la norma que fija en 25 años la edad mínima para adoptar.
} 
comprometida la libertad de expresión, sino el tratarse de una medida que establece un tipo penal y su sanción ${ }^{25}$. En esta sentencia la Corte aplica expresamente el criterio de inversión de la carga de la argumentación, para atribuirla en este caso al legislador, y además eleva los estándares de aplicación de los subprincipios de proporcionalidad al señalar que la finalidad no ha de ser sólo legítima e importante, sino también imperiosa, que el medio escogido debe ser no sólo adecuado y efectivamente conducente, sino además necesario, o sea, que no pueda ser remplazado por un medio alternativo menos lesivo. Adicionalmente, se debe aplicar un juicio de proporcionalidad en sentido estricto mediante el cual se verifique que los beneficios de adoptar la medida excedan claramente las restricciones impuestas sobre otros principios y derechos.

Para tratar de establecer el alcance que la Corte ha dado a cada uno de los juicios que integran el principio de proporcionalidad, resulta ilustrativo examinar casos en los que ha declarado la inexequibilidad de normas por no satisfacer los requisitos de idoneidad, necesidad y proporcionalidad en sentido estricto. En este punto me limito a exponer los desarrollos del juicio de proporcionalidad desde la perspectiva de "probibición de exceso":

a. Inconstitucionalidad de medidas por falta de idoneidad para proteger un fin legítimo:

Ya en la temprana sentencia C-275/1993 (M.P. A. Barrera Carbonell) se declara inconstitucional el incremento de pena para el delito de lanzamiento de sustancias u objetos peligrosos, realizado mediante un decreto de conmoción interior, por considerar que el carácter necesariamente transitorio de esta figura de excepción tornaba inidóneo el incremento punitivo en cuestión. Entretanto, en la sentencia C-205/2003 (M.P. C.I. Vargas) se declara inexequible la norma que penalizaba, como una modalidad de receptación, el comercio de autopartes usadas sin demostrar su procedencia lícita. Se argumenta que, además de vulnerar el principio de estricta legalidad, dicha norma supone una afectación injustificada de la libertad personal, que no se orienta a la protección de un bien jurídico constitucionalmente garantizado, toda vez que penaliza la conducta de quien realiza una actividad socialmente adecuada (comerciar con autopartes usadas), pero no logra demostrar la procedencia lícita de estos bienes. En tales condiciones, la norma enjuiciada deviene inidónea para alcanzar un fin constitucionalmente legítimo pues, como señala la Corte en esta sentencia:

El principio de proporcionalidad implica un juicio sobre la idoneidad del tipo penal, en el sentido de que este último realmente apunte a la protección de un bien jurídico constitucionalmente garantizado. Así las cosas, todos los poderes públicos se encuentran constitucionalmente obligados a respetar el principio de idoneidad, en tanto que subprincipio de aquel de proporcionalidad, en la creación o aplicación de la normatividad que permita la restricción de los derechos fundamentales y especialmente si se trata de asuntos criminales, incluso en

${ }^{25}$ En apoyo de este criterio se remite a la sentencia C-125/1996 (inconstitucionalidad de la restricción del delito de inasistencia alimentaria en casos de parentesco natural de consanguinidad), donde en realidad no se aplica el test de proporcionalidad ni se hace referencia alguna a la modulación de su intensidad. 
mayor medida que en otras materias, ya que los tipos penales deben ser considerados desde la perspectiva de su funcionalidad, esto es, desde el punto de vista de los fines que persiguen.

Siguiendo esta línea, en la sentencia C-355/2006 (M.P. J. Araujo y C. I. Vargas) la Corte declara la inconstitucionalidad de la norma que establecía una circunstancia agravante para el aborto practicado a menor de 14 años con su consentimiento, por su falta de idoneidad para cumplir con la finalidad de protección a las madres menores. La Corte sostiene que:

Esta medida de protección se revela incluso como contraproducente, y no resultaría idónea para conseguir el propósito perseguido, en aquellos eventos que sea necesario practicar un aborto para garantizar la vida o la salud de una menor embarazada. En efecto, dada la presunción establecida por el legislador cualquier persona que practique un aborto en una menor de catorce años sería autor del delito tipificado en el artículo 123 del Código Penal, aun cuando esta intervención sea necesaria para proteger la vida y la salud de la menor y sea consentida por la gestante.

b. Inconstitucionalidad de normas penales por falta de necesidad:

En líneas generales, la Corte ha eludido la realización del juicio de necesidad cuando aplica el principio de proporcionalidad al control de normas penales desde la perspectiva de la prohibición de exceso, argumentando la exclusiva competencia del legislador para definir los medios a través de los cuales pretende alcanzar los fines que se propone. Sin embargo, en dos sentencias recientes la Corte ha declarado la inconstitucionalidad de normas penales aduciendo su falta de necesidad:

En la sentencia C-417/2009 (M.P. J. C. Henao Pérez), se declaró inconstitucional la exclusión de la exceptio veritatis para los delitos de calumnia cuando se haya proferido sentencia absolutoria, preclusión de la investigación, cesación de procedimiento o sus equivalentes. Entre otras razones, se argumentó la existencia de otras alternativas, distintas al derecho penal, para alcanzar el fin legítimo perseguido de proteger el buen nombre y la honra de los individuos, razón por la cual resulta innecesario y excesivo imponer la limitación prevista en el art. 224 num. $1^{\circ}$ del Código Penal. Por su parte, en la sentencia C-575/2009 (M.P. H. Sierra Porto) la Corte declaró la inconstitucionalidad del delito de ultraje a símbolos patrios argumentando la existencia de medidas de protección alternativas (sanciones establecidas en el Código de Policía) que hacían innecesario el recurso al derecho penal. Sostiene que:

La remisión al derecho penal como estatuto sancionatorio debe operar únicamente cuando las medidas incorporadas para controlar los fenómenos antisociales han sido puestas en marcha sin éxito o cuando éstas son insuficientes para someterlos. El derecho penal está enmarcado en el principio de mínima intervención, lo que supone que el ejercicio del poder de punición tiene que ser el último recurso disuasivo que puede utilizar el Estado para controlar desmanes transgresores de la vida en comunidad. 
Lo interesante de estos pronunciamientos es que aquí las referencias al carácter de última ratio del derecho penal no constituyen un mero obiter dictum sino una de las ratione decidendi del fallo, razón por la cual constituye un precedente que vincula a la Corte en la decisión de casos futuros.

\section{c. Proporcionalidad en sentido estricto:}

En materia penal la Corte suele identificar el juicio de proporcionalidad en sentido estricto con la exigencia de proporción entre la gravedad del delito tipificado por el legislador y la gravedad de la pena con la que se conmina. Como principal criterio de ponderación emplea la sanción prevista para comportamientos de gravedad similar. En muchas ocasiones la Corte efectúa directamente esta ponderación prescindiendo de la realización de los juicios previos de legitimidad del fin, idoneidad y necesidad.

Así, en la sentencia C-364/1996 (M.P. C. Gaviria Díaz), la Corte emplea argumentos de proporcionalidad para declarar inconstitucional la norma de la Ley No 228 de 1993 que establecía para la contravención de hurto calificado un tratamiento punitivo más severo del que merecía la misma conducta cuando, por su cuantía, era calificada como un delito. Siguiendo una argumentación similar, la sentencia C-746/1998 (M.P. A. Barrera) declaró parcialmente inexequibles las normas de la misma ley que consagraban un trato más severo a las personas que cometieran la contravención especial de hurto simple agravado, respecto a los procesados por el delito de hurto simple agravado, pues "mientras a las primeras no se les permite la extinción de la acción penal por la reparación integral del daño causado a la víctima, sino simplemente la disminución de la pena, a las segundas sí se les admite que puedan acudir al referido mecanismo procesal".

Por su parte, en la sentencia C-070/1996 (M.P. E. Cifuentes Muñoz) se declaró la exequibilidad condicionada de la norma del Código Penal de 1980 que establecía una circunstancia genérica de agravación para el hurto sobre bienes de valor mayor a cien mil pesos. En esta sentencia la Corte sostuvo que una interpretación literal de dicha norma generaba un aumento de penas para los delitos contra el patrimonio económico, en desmedro de la libertad personal, como consecuencia exclusiva del fenómeno de pérdida de poder adquisitivo de la moneda, lo que suponía un tratamiento punitivo irrazonable y contrario al principio de proporcionalidad entre la ofensa y la sanción ${ }^{26}$.

En la sentencia C-371/2002 (M.P. R. Escobar) se declara la inexequibilidad de la norma que imponía al sindicado la obligación de observar buena conducta como condición para no revocar la libertad provisional, así como la exequibilidad condicionada de la misma obligación impuesta al condenado a quien se concede la suspensión de la ejecución de la pena de prisión. En ambos casos, la Corte efectúa una ponderación que le lleva a concluir que, en el primer caso, se produce una afectación desproporcionada de los derechos al libre desarrollo de la personalidad, la intimidad y la libertad y, en el caso de los condenados, a concluir que la restricción a tales derechos impuesta por la

${ }^{26}$ Véanse además las sentencias C-118/1996 y C-148/1998, donde la Corte se pronuncia en relación con la constitucionalidad de normas penales que establecen circunstancias de agravación similares. 
obligación de observar buena conducta sólo es constitucional si se interpreta en sentido estricto, esto es, que en cada caso el juez debe fundamentar por qué la infracción a alguno de los deberes jurídicos que dotan de contenido a la genérica obligación de observar buena conducta constituye una razón que haga necesario revocar el subrogado penal e imponer el cumplimiento de la pena de prisión.

Finalmente, en la sentencia C-355/2006 (M.P. J. Araujo y C. I. Vargas) se emplean argumentos de proporcionalidad para considerar que "la probibición completa e incondicional del aborto en todas las circunstancias es abiertamente desproporcionada porque anula completamente derechos de la mujer embarazada garantizados por la Constitución de 1991 y por tratados internacionales de derechos humanos que hacen parte del bloque de constitucionalidad" 27.

\subsection{Perspectiva cuantitativa}

A partir de un rastreo de información en el buscador de la Corte Constitucional, seleccioné como muestra el total de sentencias proferidas con ocasión del control constitucional de las normas del Código Penal (Ley No 599 de 2000) hasta agosto de 2010. Aunque, debido al volumen de sentencias, no se contabilizan aquellas proferidas con ocasión del control de legislación penal complementaria, en todo caso la muestra examinada es suficientemente representativa como para dar una idea del lugar que ocupa el principio de proporcionalidad en el control constitucional de las normas penales sustantivas.

La Corte ha expedido 82 sentencias donde examina la constitucionalidad de normas del Código Penal (Ley No 599 de 2000), con ocasión de demandas de constitucionalidad interpuestas por los ciudadanos. De estas sentencias, 22 son inhibitorias (por ineptitud de la demanda o porque ordena estarse a lo resuelto en sentencias anteriores en las que ya se había pronunciado sobre la constitucionalidad de las normas demandadas). De los 60 pronunciamientos de fondo, en 40 declara la exequibilidad (constitucionalidad) pura y simple de las normas demandadas, en 11 su inexequibilidad (inconstitucionalidad), en 8 sentencias su exequibilidad condicionada y en 1 sentencia declara la existencia de una omisión legislativa, exhortando al Congreso para que la subsane.

De esos 60 pronunciamientos de fondo, en 39 se excluye por completo toda referencia al principio de proporcionalidad. En 21 se menciona el principio de proporcionalidad, pero sólo en 15 de ellos se utiliza (con mayor o menor rigor argumentativo) como fundamento de la decisión. En los demás casos la mención constituye un mero obiter dictum del que no se extraen consecuencias para la fundamentación del fallo. De las 15 sentencias

${ }^{27}$ En consecuencia, se declara la constitucionalidad condicionada del artículo 122 del Código Penal, en el entendido de que no se incurre en delito de aborto, cuando con la voluntad de la mujer la interrupción del embarazo se produzca en los siguientes casos: (i) Cuando la continuación del embarazo constituya peligro para la vida o la salud de la mujer, certificada por un médico; (ii) Cuando exista grave malformación del feto que haga inviable su vida, certificada por un médico; y (iii) Cuando el embarazo sea el resultado de una conducta, debidamente denunciada, constitutiva de acceso carnal o acto sexual sin consentimiento, abusivo o de inseminación artificial o transferencia de óvulo fecundado no consentidas o de incesto. 
en las que se utilizó, 7 declararon la constitucionalidad de las normas demandadas, 4 su constitucionalidad condicionada, 2 su inconstitucionalidad, 2 combinaron pronunciamientos de inconstitucionalidad y constitucionalidad condicionada.

A partir de los ejemplos considerados en el análisis cualitativo realizado en el epígrafe anterior, parecería que la utilización del principio de proporcionalidad en el control abstracto de las normas penales constituye una práctica plenamente consolidada en la jurisprudencia constitucional colombiana. Pero esta conclusión se debilita a la luz de las cifras que resultan del análisis cuantitativo antes mencionado, donde sólo una cuarta parte de las sentencias de fondo analizadas realmente emplean argumentos de proporcionalidad como fundamento de la decisión.

En líneas muy gruesas, este examen cuantitativo deja ver que la utilización del principio de proporcionalidad en el control de constitucionalidad de las normas penales no constituye una práctica sistemática y plenamente consolidada, sino que el recurso a esta herramienta es variable y acaso depende de factores tales como: (i) el estilo argumentativo de los magistrados ponentes ${ }^{28}$; (ii) la estrategia de elaboración de las demandas de constitucionalidad ${ }^{29}$ y (iii) el tipo de casos a resolver.

En relación con este último criterio, es claro que la utilización del principio de proporcionalidad en el control de normas penales sustantivas está excluida en los casos en que se discuten vicios de procedimiento o infracción a límites formales al poder punitivo, como las exigencias derivadas del principio de legalidad ${ }^{30}$. Sin embargo, su empleo tendría cabida en todos los casos en los que se plantea una colisión entre el bien jurídico que el legislador busca proteger y los derechos fundamentales que se ven afectados por la tipificación de la conducta prohibida y la determinación de la pena a imponer.

Una vez situados en este universo de casos, la comparación entre el tipo de casos en los que la Corte Constitucional emplea a fondo el principio de proporcionalidad y

${ }^{28}$ Aunque en sus inicios el empleo de herramientas argumentativas como el "principio de proporcionalidad" o el "test de razonabilidad" fue impulsado por magistrados como Eduardo Cifuentes Muñoz o Carlos Gaviria Díaz, identificados como parte del bloque liberal-progresista de la Corte Constitucional, lo cierto es que tales estrategias argumentativas pronto se hicieron comunes en otros despachos, y su utilización se ha mantenido relativamente inalterada en los sucesivos cambios de composición de la Corte. Incluso magistrados que en principio formularon críticas vehementes al uso de dicha herramienta (como es el caso de Jaime Araujo, en su Aclaración de Voto a la sentencia C-673/01), posteriormente la emplean en la fundamentación de sus decisiones. Dado este uso generalizado, aunque selectivo, del principio de proporcionalidad, en la actualidad difícilmente cabe identificar el recurso a esta herramienta como una señal de estilo argumentativo de ciertos magistrados (aun cuando algunos despachos se caracterizan por una mayor frecuencia y rigor en su utilización) y, menos aún, como indicador de su pertenencia a un determinado sector ideológico de la Corte Constitucional.

${ }^{29}$ En tanto la utilización del principio de proporcionalidad por parte de los ciudadanos como derrotero argumentativo para formular los cargos de constitucionalidad estimula que la Corte emplee esta misma herramienta para abordar su estudio en la sentencia.

30 Sobre la incapacidad del principio de proporcionalidad para incorporar las exigencias derivadas del principio de proporcionalidad llama la atención Mir Puig, S., "El principio de proporcionalidad como fundamento constitucional de límites materiales del Derecho Penal”. En: J. C. Carbonell Mateu, J.L. González Cussac, E. Orts Berenguer (Dir.), Constitución, Derechos Fundamentales y Sistema Penal (Semblanzas $y$ estudios con motivo del setenta aniversario del profesor Tomás Salvador Vives Antón), Tomo II, Valencia, Tirant Lo Blanch, 2009, p. 1362. 
aquellos en los que no lo hace, permite llamar la atención sobre la utilización selectiva de esta herramienta argumentativa en la jurisprudencia constitucional colombiana.

\subsection{Perspectiva comparativa}

El sentido de las sentencias de constitucionalidad hasta ahora examinadas parecería indicar que, en lugar de la deferencia hacia el legislador que suelen adoptar otros Tribunales Constitucionales, entre ellos el chileno, la Corte Constitucional colombiana mantiene un elevado listón de exigencia en el examen de constitucionalidad de la legislación penal, sin encontrar reparo alguno en excluir del ordenamiento aquellas normas que no satisfagan los criterios de idoneidad, necesidad y estricta proporcionalidad. Conclusión que, por lo demás, vendría alimentada por la percepción de mayor activismo que se atribuye a la Corte colombiana en relación con la de sus homólogos latinoamericanos. Sin embargo, esta percepción contrasta con otros casos en los que la Corte deliberadamente omite verificar las exigencias derivadas del principio de proporcionalidad, o bien las menciona a la manera de artefacto retórico que sólo se apoya en hueras peticiones de principio.

Uno de estos ejemplos lo constituye la sentencia C-689/2002 (M.P. A. Tafur Galvis), en la que se resuelve demanda de constitucionalidad frente a varias normas del Código Penal que tipifican conductas relacionadas con el narcotráfico ${ }^{31}$. Entre otros argumentos, el demandante sostiene que dichas normas vulneran el principio de igualdad, al discriminar a quienes producen o comercializan estupefacientes, estableciendo sanciones penales no previstas para los comerciantes de bebidas alcohólicas y de tabaco. Asimismo, cuestiona la constitucionalidad del artículo 385 C.P., norma que anticipa las barreras de punición hasta sancionar con prisión de 4 a 10 años y multa de 100 a 1000 salarios mínimos la construcción de pistas de aterrizaje o la iniciación o aterrizaje de vuelos sin la correspondiente autorización administrativa. El demandante argumenta que la penalización de estas conductas contraría el principio de proporcionalidad de las penas, por tratarse de comportamientos que en sí mismos no lesionan el bien jurídico que el legislador pretende proteger y que, a lo sumo, merecerían el tratamiento de contravenciones administrativas.

En esta sentencia, la Corte sostiene que "la despenalización del narcotráfico no es un asunto que pueda ser resuelto en sede de control constitucional", por cuanto se trata de una decisión político criminal que corresponde adoptar al legislador, la cual, en sí misma considerada, no puede ser objeto de control constitucional, por cuando ello trasladaría a la Corte el poder de imponer, a través de sus fallos, el modelo de política criminal que esta juzgue preferible. Siguiendo esta línea de extrema deferencia, la Corte se abstiene de examinar el cargo por violación al principio de igualdad propuesto por el demandante, afirmando que "acceder a un juicio de igualdad, en relación con la penalización del narcotráfico, sería invadir por parte de la Corte, una competencia constitucional propia del Congreso de la República, que se reitera, está señalada expresamente por la propia Carta al Legislador para

\footnotetext{
${ }^{31}$ Se trata de los artículos 375, 376, 377, 378, 379, 380, 382 y 385 de la Ley N $^{\circ} 599$ de 2000.
} 
que éste, en el marco de su potestad de configuración, pueda diseñar el sistema penal con arreglo a la política criminal que se le ha encomendado".

Esta negativa a enjuiciar la constitucionalidad de las diferencias establecidas por el legislador en desarrollo de su política criminal contrasta con la actitud adoptada por la Corte en anteriores ocasiones, donde no ha tenido reparos en saltarse la veda impuesta a sus competencias por el principio de legalidad, para corregir por mano propia, en aplicación del principio de igualdad, tipos penales que consideraba incompletos ${ }^{32} \mathrm{o}$ penas que consideraba desproporcionadas por defecto ${ }^{33}$.

Finalmente, en lo que respecta al cargo por violación al principio de proporcionalidad del artículo 385 del C.P., la Corte se limita a señalar "que en la norma demandada se haya establecido un delito y no una contravención, revela solamente que la frecuencia con que se construyen pistas de aterrizaje o se efectúan vuelos no autorizados por la Unidad Administrativa Especial de aeronáutica civil y la incidencia que ello tienen en el tráfico de estupefacientes, imponía incrementar el rigor punitivo para sancionar esas conductas, con el fin de y asegurar un mayor ámbito de protección para el bien jurídico salud pública". Sin embargo, contrario a lo que constituye su proceder habitual en otros ámbitos, en esta ocasión elude examinar la idoneidad, necesidad y estricta proporcionalidad de la intervención legislativa, pese a que así lo reclamaba la estructuración del cargo propuesta en la demanda.

Esta decisión pone de manifiesto que el activismo que ha caracterizado a la Corte Constitucional colombiana encuentra un importante límite en el control de las decisiones que definen las líneas centrales de la política criminal. En ellas el ideal de sujeción de la política a los derechos, que constituye el leitmotiv del estado constitucional, se topa con la barrera infranqueable de decisiones político criminales que parecerían constituir un auténtico "coto vedado" al control constitucional. Así ocurre especialmente en relación con aquellas materias, como el narcotráfico, en las que el Estado ha asumido compromisos internacionales de criminalización ${ }^{34}$, caso en el cual las normas que introducen tales mandatos operan en el razonamiento de la Corte como reglas, que imponen deberes de penalización definitivos, en lugar de como principios que deben ser ponderados con las

32 En la C-125/1996 (M.P. J. Arango Mejía) se consideró que la limitación del tipo penal de inasistencia alimentaria al incumplimiento de tal obligación entre "padres e hijos", excluyendo así a otros ascendientes y descendientes beneficiarios de este derecho según la legislación civil, vulneraba el principio de igualdad. Con este argumento, se procede a extender, por vía jurisprudencial, el ámbito de aplicación del tipo penal en cuestión para asegurar penalmente el cumplimiento de esta obligación frente a todos sus beneficiarios.

33 Así ocurre en las sentencias C-287/1997 ( M.P. C. Gaviria Díaz) referida a la atenuante punitiva para la violencia sexual cometida contra cónyuge, y la C-358/1997 (M. P. E. Cifuentes Muñoz), en la que se examina el tratamiento punitivo más benigno para el homicidio cometido por militares frente al cometido por civiles. En ambos casos, ante una desigualdad punitiva que se considera injustificada, la Corte declara inconstitucional la pena menor y, por vía de una sentencia manipulativa, la reemplaza por la pena mayor.

${ }^{34}$ Así lo admite la Corte en la sentencia C-689/2002 (M.P. A. Tafur) cuando, en respuesta al argumento relativo al trato desigual dado al narcotráfico respecto de la fabricación y comercialización de otras sustancias nocivas como el alcohol y el tabaco, la Corte sostiene que, en este caso "se está en presencia de una serie de compromisos internacionales que obligan al Estado colombiano a combatir el narcotráfico, circunstancia que establece una diferencia relevante para el tratamiento de uno y otro tipo de situaciones". 
razones en contra de la criminalización representadas por los derechos fundamentales que se ven afectados por las prohibiciones y las sanciones penales.

\section{Conclusiones}

El diseño de sistemas de justicia constitucional, así como sus modos de funcionamiento efectivo, representan intentos de resolver la tensión entre constitucionalismo y democracia inherente al modelo de estado constitucional. En el debate teórico sobre cuál puede ser el diseño institucional que mejor acomode ambas exigencias ha ganado terreno la tesis que descarta una respuesta general y, en cambio, admite la "dependencia contextual", de modo tal que, como sostiene Juan Carlos Bayón, si "la justificación de un diseño institucional depende de un balance entre su valor intrínseco y su valor instrumental, se ha de admitir que cuál sea el diseño institucional preferible es una cuestión inevitablemente dependiente del contexto, de manera que para diferentes condiciones sociales habrá que considerar justificados procedimientos de decisión distintos" 35 .

Lo anterior no sólo vale, en el sentido que propone Bayón, para discutir sobre la pertinencia de adoptar un modelo de constitucionalismo "débil", que reserve la última palabra a las mayorías parlamentarias, o un modelo "fuerte" que establezca mecanismos de rigidez y control judicial de constitucionalidad de las leyes. La tesis de la "dependencia contextual" también ha de ser considerada cuando se trata de examinar la postura de mayor o menor deferencia que adopta el Tribunal Constitucional respecto del Legislador en aquellos sistemas que han optado por introducir sistemas de justicia constitucional. Al fin y al cabo, el nivel de exigencia y la intensidad del control de constitucionalidad de las leyes contribuyen de manera importante a definir el carácter "débil" o "fuerte" de un diseño concreto de constitucionalismo.

Un análisis comparado de las circunstancias sociales, políticas y culturales que permitan comprender la postura de mayor protagonismo institucional en el control de constitucionalidad de las leyes que ha distinguido a la Corte Constitucional colombiana, en relación con la deferencia hacia el legislador que caracteriza a su homólogo chileno, excedería el objeto del presente trabajo. Por eso en este caso me limito a sugerir, desde la perspectiva de una observadora externa, que acaso la decidida y constante deferencia hacia el legislador mantenida por el Tribunal chileno sea el resultado del arreglo institucional establecido en este país, que prefiere reservar la última palabra al legislador en lugar de confiarla a una institución contramayoritaria en la que no deposita mayores esperanzas dado que, en sí misma, no garantiza un nivel de racionalidad mayor de la que cabe esperar de las deliberaciones parlamentarias ${ }^{36}$. En el caso colombiano, el

${ }^{35}$ Bayón, J. C., "Democracia y derechos: problemas de fundamentación del constitucionalismo", en M. Carbonell y L. García Jaramillo (edits.), El canon neoconstitucional, Bogotá, Universidad Externado de Colombia, 2010, pp. 409-476, aquí p. 473.

${ }^{36}$ En esta dirección parece encaminarse la tesis sostenida por José Ángel Fernández, cuando en el título de uno de sus trabajos sugiere un incremento de la legitimidad democrática como medio para mitigar la 
mayor protagonismo y la menor deferencia que asume la Corte Constitucional frente al legislador no es percibida como una amenaza a la democracia sino que, en un contexto de progresiva desinstitucionalización como el que tuvo lugar en el pasado reciente, la Corte se erigió en uno de sus principales baluartes ${ }^{37}$. Por eso, pese a las críticas que algunos sectores de opinión formulan en contra de su activismo, resulta ser una de las instituciones públicas mejor valoradas entre los colombianos ${ }^{38}$.

Lo que no depende del contexto es la necesidad de elevar la calidad de la argumentación, pues de ella depende en buena medida la legitimidad de las decisiones de la justicia constitucional. Y esta exigencia no decae, como parecen asumirlo tanto el Tribunal chileno como la Corte colombiana, cuando se trata de darle la razón a las decisiones del legislador penal, pues en este caso es menester justificar no sólo ante los individuos concretos sobre los que recaerá el peso de la aplicación de las leyes penales, sino ante todos los ciudadanos, potencialmente sujetos al poder punitivo del Estado, por qué sus derechos fundamentales pueden ser limitados por una decisión legislativa, cuando precisamente aquellos prometen servir como "cotos vedados" al poder de las mayorías.

En esa empresa de dar razones, el principio de proporcionalidad puede prestar una modesta contribución, siempre que no se utilice como mampara para ocultar hueras peticiones de principio $^{39}$, sino dando razones que respalden los juicios de idoneidad, necesidad o de proporcionalidad en sentido estricto. Empleado de este modo, el principio de proporcionalidad podría ayudar a incrementar no sólo las exigencias de racionalidad que se plantean al legislador en la elaboración de las leyes ${ }^{40}$, sino las propias exigencias argumentativas que debe satisfacer el Tribunal Constitucional como condición para legitimar sus decisiones.

irracionalidad inherente al control constitucional, y al proponer que, en casos excepcionales, el Parlamento se constituya en el intérprete último de la Constitución. Fernández Cruz, J. A., "El juicio constitucional de proporcionalidad de las leyes penales....", citado, p. 94.

${ }^{37}$ Baste mencionar como ejemplos las sentencias C-816/2004 (M.P. J. Córdoba Triviño y R. Uprimny), que declaró la inconstitucionalidad del Estatuto Antiterrorista, y la C-141/2010 (M.P. H. Sierra Porto), que puso freno a la reforma constitucional que buscaba introducir el referendo para la segunda reelección del presidente Álvaro Uribe.

${ }^{38}$ Según datos de una encuesta realizada en 2009, la Corte alcanzaba un índice de popularidad del $61 \%$. Ver: http://www.semana.com/wf_ImprimirArticulo.aspx?IdArt=121395 (consultada el 2 de abril de 2011).

${ }^{39}$ Como ocurre cuando la argumentación se limita a señalar que la medida es idónea porque contribuye a alcanzar un fin legítimo; necesaria porque no existen medios alternativos igualmente eficaces para alcanzar el fin y menos lesivos para los derechos afectado; proporcional en sentido estricto, porque la afectación de los derechos se ve compensada por la protección de otros derechos o bienes constitucionalmente valiosos.

${ }^{40}$ En tal sentido vid. Marcilla Córdoba, G., Racionalidad legislativa. Crisis de la ley y nueva ciencia de la legislación, Madrid, CEPC, 2005, pp. 334-343; en sentido crítico, Díez Ripollés, J. L., La racionalidad de las leyes penales, Madrid, Trotta, 2003, pp. 127-131. 


\section{BIBLIOGRAFÍA}

Allouch, J., El sexo del amo, Buenos Aires, El Cuenco de Plata, 2009.

BAYón, J. C., "Democracia y derechos: problemas de fundamentación del constitucionalismo", en M. Carbonell y L. García Jaramillo (edits.), El canon neoconstitucional, Bogotá, Universidad Externado de Colombia, 2010.

Caballero Brun, F., "Derecho Penal sustantivo y efectos en el tiempo de la sentencia del Tribunal Constitucional que declara la inconstitucionalidad de un precepto penal", en Revista de Derecho (Valdivia), vol. XIX, 2006.

Díez Ripollés, J. L., La racionalidad de las leyes penales, Madrid, Trotta, 2003.

Fernández Cruz, J. A., "El juicio constitucional de proporcionalidad de las leyes penales: la legitimación democrática como medio para mitigar su inherente irracionalidad”, en Revista de Derecho Universidad Católica del Norte, Año 17, No. 1, 2010.

Fernández CruZ, J. A., "La incorporación del juicio proporcionalidad en el control constitucional de las leyes penales: el recurso de inaplicabilidad del art. 450 inciso $1^{\circ}$ del Código Penal, rol 825”, ponencia en el Coloquio sobre Jurisprudencia Constitucional, Universidad Católica de Valparaíso, 9 y 10 de octubre de 2008 (ponencia pendiente de publicación).

Ferreres Comella, V., "El control judicial de la constitucionalidad de la ley. El problema de su legitimidad democrática”, en M. Carbonell y L. García Jaramillo (edits.), El canon neoconstitucional, Bogotá, Universidad Externado de Colombia, 2010.

Ferreres Comella, V., Justicia constitucional y democracia, Madrid, Centro de Estudios Políticos y Constitucionales, 1997 ( $2^{\mathrm{a}}$. ed., 2007).

Fuentes Cubillos, H., "El principio de proporcionalidad en Derecho Penal. Algunas consideraciones acerca de su concretización en el ámbito de la individualización de la pena”, Ius et Praxis, Vol. 14, No. 2, 2008.

Marcilla Córdoba, G., Racionalidad legislativa. Crisis de la ley y nueva ciencia de la legislación, Madrid, CEPC, 2005.

Mir Puig, S., "El principio de proporcionalidad como fundamento constitucional de límites materiales del Derecho Penal”. En: J. C. Carbonell Mateu, J.L. González Cussac, E. Orts Berenguer (Dir.), Constitución, Derechos Fundamentales y Sistema Penal (Semblanzas y estudios con motivo del setenta aniversario del profesor Tomás Salvador Vives Antón), Tomo II, Valencia, Tirant Lo Blanch, 2009.

Nogueira Alcalá, H., "El derecho de igualdad ante la ley, la no discriminación y acciones positivas", Anuario da Facultad de Direito da Universidade da Coruña (AFDUC), 10, 2009.

Nogueira Alcalá, H., "El principio de proporcionalidad y su aplicación en Sudamérica por la jurisdicción constitucional, con especial mención al Tribunal Constitucional chileno”, en Carbonell, M. (coord.), El principio de proporcionalidad en la interpretación jurídica, Santiago, Librotecnia, 2010.

SAONA MARín, T., La aplicación del principio de proporcionalidad por el Tribunal Constitucional chileno en el control constitucional de normas penales. Memoria para optar al grado de Licenciado en Ciencias Jurídicas y Sociales, Valdivia, Universidad Austral, 2010. 